\title{
Using Associations based Method among Prescribed Medications in Egyptian Public Clinics
}

\author{
Marwa Zakarya \\ Helwan University \\ Department of BIS, \\ Faculty of Commerce \\ \&Business Administration
}

\author{
Yehia Helmy \\ Helwan University \\ Department of BIS, \\ Faculty of Commerce \\ \&Business Administration
}

\author{
Sherif Kholeif \\ Helwan University \\ Department of information \\ systems \\ Faculty of computers \\ \&information
}

\begin{abstract}
Paper based-prescriptions that are not entered electronically in Egyptian public clinics lead to loss the opportunity of association investigation among prescribed medications, track improper prescriptions and handle patient health record. Developing electronic prescription service can assign a positive impact in such case.

In this paper, performing data mining on data collected from paper based- prescriptions ordered by the prescriber and entered electronically as data set to analyze the associations among prescribed medications. Eleven association rules were resulted from the assigned prescribed medication in those prescriptions using the FP-Growth (frequent pattern) algorithm. The accuracy of these rules was reviewed by a clinical pharmacist. Among these association rules, Julmentin $1 \mathrm{gm}$ and Allergyl tabs are the most associated medications resulted as first ranked then Pirafene syrup and Julmentin 1gm resulted as second ranked. The results of this study indicate that developing electronic prescription service can lead to significant knowledge in prescribing patterns.
\end{abstract}

\section{General Terms}

Association based rules, appriori Algorithm, Egypt.

\section{Keywords}

Data Mining, Association Rules, FP-growth method, eprescription service, prescribing errors, clinical pharmacist, Egypt

\section{INTRODUCTION}

Healthcare systems are under pressure due to the demographic changes of population generate subsequent demand for healthcare. Accordingly, there are a trend from the governmental health sector to enhance processing system of medication therapy ,drug items and medication prescription[1].Egypt is one of the most populous countries in middle east [2] and there are a massive number of paper based- prescriptions are issued and dispensed annually for free to patients. Previous studies have revealed problems related to paper prescriptions in Egypt[3]. Improper prescribing can cause harm for patients and will be waste of money and time[4].

Nowadays, problems and limitations of paper-based prescriptions lead to find solution that eliminate deficiencies of paper prescribing using technology.

However, the transition to e- prescribing is not a single step process and in general the main actions and steps in the process of prescribing remain the same with advancing computerization level[5].Hence, the objective of this study was to analyse the current outpatient public clinic paper-based prescriptions issued as well as to clarify associations among medications.

\section{BACKGROUND}

Nowadays, many papers have been published on paper-based prescription highly rate errors[3][6][7].different methods for the optimal prescribed items in pharmacies have been proposed[8][9]. Updated databases have to be maintained in order to extract useful information and also tracking error existence. The electronic prescription service has to consider data mining issues, in which makes pattern detection easier.

Food and Drug Administration (FDA) in the United States has also used data mining methods to get information about the side effects of drugs[10].

Drugs.com repository is very useful for finding mined information for different aspects about medications[11].

\section{THE PROPOSED SYSTEM \\ ADVANTAGES AND GOALS}

The aim of the research is to propose electronic prescription service considering data mining issues among prescribed medications.

The following advantages have to be considered:

- Prescribed medications in governmental pharmacies are available within the electronic system.

- Preparing related medications in order to minimize or to avoid missing medication prescriptions and check the availability of all prescribed medications.

In this paper, FP-growth algorithm on collected prescribed medications data set was implemented, reviewing rules and analyse results.

\section{RESEARCH METHODOLOGY}

Manually collected paper-based prescriptions entered into a database in order to extract associations using FP-Growth mining method. This database should contain the TID, medication name, a dosage of each prescribed medication. In a summary, the database of this study includes 63 drug items (medications). To construct such a database, prescriptions were manually collected from public clinic pharmacy Centre in Badr city. Research Methodology was conducted through 5 steps:

1. Literature review to study previous work on E-healthcare services.

2. Design of an electronic prescription service that can enhance performance within healthcare systems. 
3. Developing an application to use FP-Growth algorithm for medical association rules finding.

4. Testing the results of the algorithm and validate by a clinical pharmacist.

5. Documentation that will be ongoing of the previous steps.

For this purpose, Rapid Miner Software includes different data mining algorithms like FP-Growth algorithm which is one of the algorithms for finding association rules was applied in this research.

\subsection{Associations based method}

Association rules are created by analyzing data for frequent if/then patterns and using the criteria support and confidence to identify the most important relationships. Support is an indication of how frequently the items appear in the database. Confidence indicates the number of times the if/then statements have been found to be true. The frequent if/then patterns are mined using the operators like the FPGrowth operator. Criterion This parameter specifies the criterion which is used for the selection of rules.
Confidence: The confidence of a rule is defined conf(X implies $\mathrm{Y})=\operatorname{supp}(\mathrm{X} \cup \mathrm{Y}) / \operatorname{supp}(\mathrm{X})$. Confidence is an estimate of $\mathrm{P}(\mathrm{Y} \mid \mathrm{X})$, the probability of observing $\mathrm{Y}$ given $\mathrm{X}$. The support $\operatorname{supp}(\mathrm{X})$ of an item set $\mathrm{X}$ is defined as the proportion of transactions in the data set which contain the item set[12].

In below figure, associations are shown by arrows and rules in rectangles.

Input data of this research is showed in the following figure of data set example:

Pt1 : \{ pirafene syrup, julmentin 1gm , mucolan syrup

Pt2 : \{ pirafene syrup, brufen tab, neopumolar $\}$

Pt3 : $\{$ candistan, pirafene syrup $\}$

Pt4 : $\{$ pirafene syrup t, neopumolar,emoxclav $457 \mathrm{mg} / 5 \mathrm{ml}\}$

Pt5 : \{brufen tab, julmentin 1gm,pirafene syrup $\}$

Fig1. the medication prescribed for 5 sample patients.

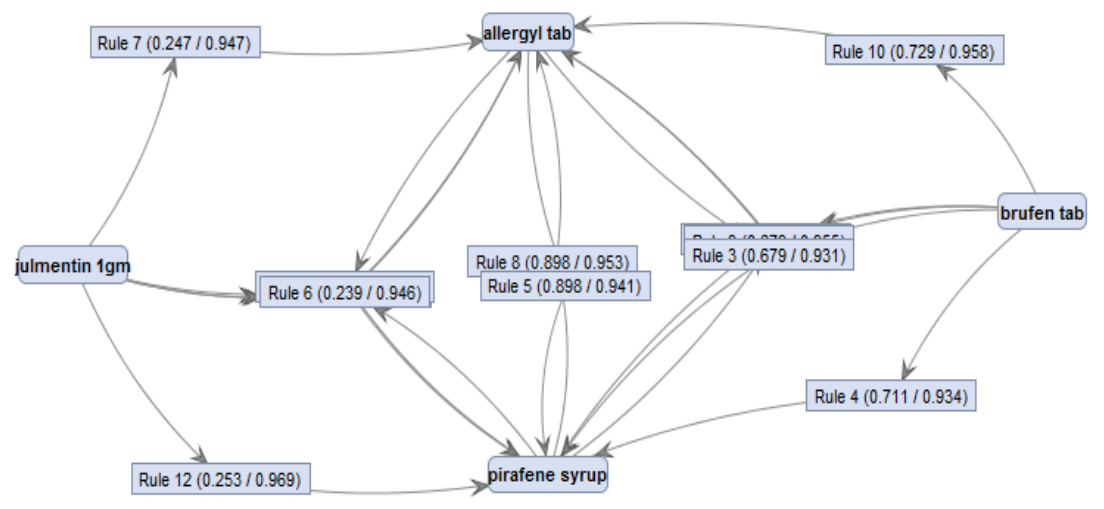

Fig. 2 Associations among prescribed medications

Table.1 show results of FP-Growth algorithm

\begin{tabular}{|c|c|c|c|c|}
\hline No. & Premises & Conclusion & Support & Confidence \\
\hline 2 & Julmentin1gm & $\begin{array}{c}\text { Allergyl tab, pirafene } \\
\text { syrup }\end{array}$ & 0.239 & 0.917 \\
\hline 3 & Allergy tab, brufen tab & Pirafene syrup & 0.679 & 0.931 \\
\hline 4 & Brufen tab & Pirafene syrup & 0.711 & 0.934 \\
\hline 5 & Alleryl tab & Pirafene syrup & 0.898 & 0.941 \\
\hline 6 & Pirafene syrup, julmentin 1gm & Allergy tab & 0.239 & 0.946 \\
\hline 7 & Julmentin 1gm & Allergy tab & 0.247 & 0.947 \\
\hline 8 & Pirafene syrup & Allergy tab & 0.898 & 0.953 \\
\hline 9 & Pirafene syrup, brufen tab & Allergy tab & 0.679 & 0.955 \\
\hline 10 & Brufen tab & Allergy tab & 0.729 & 0.958 \\
\hline 11 & Allergy tab, julmentin 1gm & Pirafene syrup & 0.239 & 0.968 \\
\hline 12 & Julmentin 1gm & Pirafene syrup & 0.253 & 0.969 \\
\hline
\end{tabular}

Data set were converted into True and False (T\&F) CSV file, which was then applied as the input source in the rapid miner. The stored data was retrieved and selected attributes have been done among 2640 records entered electronically in database excluding 360 records because only one prescribed medication found. Eleven rules were obtained after the implementation of our proposed $\mathrm{Fp}$-Growth algorithm, which was shown as premises and conclusion Associations in the above table. 


\section{RESULTS}

Table 1.shows the obtained association rules. Then, the obtained rules are studied

\section{Rules 7 and 2:}

(7) If Julmentin $1 \mathrm{gm}$ then Allergyl tablet;

(2) If Pirafene syrup then Julmentin $1 \mathrm{gm}$.

The obtained results show that both Julmentin $1 \mathrm{gm}$ and Allergyl tablet had maximum confidence coefficient and were given on the table. Both of these drugs were prescribed for elder patients in internal speciality.

Rule 3:

(3) If Pirafene syrup cannot be dispensed then allergy tab for elder patient.

Rule (4\&9):

If Brufen tab then Pirafene syrup

This rule states that if Brufen tab is prescribed for a patient, then Pirafene syrup will be also prescribed with the confidence coefficient of 0.934 .

\section{Rule 5:}

(5) Allergy tab or Pirafene syrup

Allergy tab is used for treatment of allergic to grass or ragweed pollen. Different tablets are approved for specific ages[13]

Pirafene is indicated for symptomatic relief of allergic reactions due to hay fever, urticaria and anaphylactoid reactions due to pollen grains, dust, food, drugs and allergic rhinitis.

Both not associated with each other[14]

\section{Rule (6\&7):}

(6) If pirafene syrup and julmentinel gm tab then not associated with allergy tab

Julmentine1gm tab should be used only to treat or prevent infections that are proven or strongly suspected to be caused by bacteria.

\section{Rule 10:}

(10) If Brufen not dispensed then allergy tab can be used.

Interchangeably association.

\section{Rule 11:}

(11) If Allergy \&Julmentin $1 \mathrm{gm}$ tab item set then No dispensing of pirafene syrup.

\section{CONCLUSIONS}

Analysis among prescribed medications in public clinic pharmacy is the objective of this paper. Mining the associations between medications which are prescribed together can be found using prescribed medications database that is collected manually based on patient's illness and symptoms described to physician in Egyptian public clinic Centre in Badr city. For this purpose, a data mining tool is used. Some of the association rules are identified by applying the Fp-Growth algorithm. It was analyzed that Julmentin 1gm and Allergyl tabs are the most correlated medications, and Pirafene syrup and Julmentin $1 \mathrm{gm}$ were arranged in the second term of associations.

The most important problem addressed in this research is the data collection which is done with difficulty, to keep medication prescriptions manually as documented paperbased prescription. As a result we proposed an electronic prescription service to be implemented, which leads to a medication prescribed database using mining tools that help to find knowledge about dispensed prescribed medications to physician and clinical pharmacist as decision support tool.

\section{ACKNOWLEDGMENTS}

We sincerely thank Dr. Ayman Taha who help us during this research and giving scientific support.

\section{REFERENCES}

[1] MCIT, "ICT for Health." [Online]. Available: http://www.mcit.gov.eg/Digital_Government/ICT_for_H ealth.

[2] I. Rank and P. C. Gross, "Egypt," no. 2005, pp. 0-1, 2010.

[3] Z. H. A. Shehata, N. A. Sabri, and A. A. Elmelegy, "Descriptive analysis of medication errors reported to the Egyptian national online reporting system during six months," J. Am. Med. Informatics Assoc., vol. 23, no. 2 , pp. 366-374, 2016.

[4] O. H. Mohamed Ibrahim, "The Impact of Clinical Pharmacist Interventions on Drug and Antibiotic Prescribing in a Teaching Hospital in Cairo," Pharmacol. \&amp; Pharm., vol. 03, no. 04, pp. 458-461, 2012.

[5] M. Ahmadi, M. Samadbeik, and F. Sadoughi, "Modeling of outpatient prescribing process in Iran: A gateway toward electronic prescribing system," Iran. J. Pharm. Res., vol. 13, no. 2, pp. 725-738, 2014.

[6] N. A. Sabry and M. M. Abbassi, "Impact of a Clinical Pharmacist in the General Hospital : An Egyptian Trial," no. June, pp. 577-587, 2014.

[7] H. Khalili, S. Farsaei, H. Rezaee, and S. DashtiKhavidaki, "Role of clinical pharmacists' interventions in detection and prevention of medication errors in a medical ward," Int. J. Clin. Pharm., vol. 33, no. 2, pp. 281-284, 2011

[8] S. Doddi, A. Marathe, S. S. Ravi, and D. C. Torney, "Discovery of Association rules in Medical Data," Miim, vol. 26, no. 1, pp. 25-34, 2000.

[9] T. Action and P. Guide, "Focus on ...," vol. 8, no. 3, pp. 199-202, 2008

[10] H. J. Duggirala, J. M. Tonning, E. Smith, R. A. Bright, J. D. Baker, R. Ball, C. Bell, K. Bouri, S. J. Bright-Ponte, T. Botsis, M. Boyer, K. Burkhart, G. S. Condrey, J. J. Chen, S. Chirtel, R. W. Filice, H. Francis, H. Jiang, J. Levine, D. Martin, T. Oladipo, R. O'Neill, L. A. M. Palmer, A. Paredes, G. Rochester, D. Sholtes, H.-L. Wong, Z. Xu, A. Szarfman, and T. Kass-Hout, "Data Mining at FDA," no. Cvm, pp. 1-24, 2015.

[11] "drugs data repository." [Online]. Available: www.drugs .com.

[12] "associations based method." [Online]. Available: http://docs.rapidminer.com/studio/operators/modeling/as sociations/create_association_rules.html.

[13] "allergyl indications." [Online]. Available: http://acaai.org/allergies/allergy-treatment/sublingualimmunotherapy-slit/allergy-tablets-sublingualimmunotherapy.

[14] "pirafene indications." [Online]. Available: http://memphis.com.eg/en/products/injection/73.html. 